\title{
Strategic Firm Interaction, Returns to Scale, Environmental Regulation and Ambient Charges in a Cournot Duopoly
}

\author{
Sudhakar Raju1, Subhadra Ganguli ${ }^{2}$ \\ ${ }^{1}$ Helzberg School of Management, Rockhurst University, Kansas City, USA \\ ${ }^{2}$ Bahrain Institute of Banking \& Finance (BIBF), Manama, Bahrain \\ Email: sudhakar.raju@rockhurst.edu,sganguli@bibf.com
}

Received January 18, 2013; revised March 14, 2013; accepted March 21, 2013

Copyright (C) 2013 Sudhakar Raju, Subhadra Ganguli. This is an open access article distributed under the Creative Commons Attribution License, which permits unrestricted use, distribution, and reproduction in any medium, provided the original work is properly cited.

\begin{abstract}
Environmental regulation under conditions of imperfect competition in the presence of nonpoint sources (NPS) of pollution has not been well analyzed in the literature. This paper models strategic firm interaction and the effect of ambient charges on total NPS pollution in an imperfectly competitive, Cournot type duopoly under constant and decreasing returns to scale (CRTS \& DRTS). We identify two distinct and often opposing effects. Under CRTS, the primary effect of a higher ambient charge is to increase pollution abatement (and thus decrease pollution) while the secondary effect is to lower output. Higher pollution abatement and lower output reinforce each other so that a higher ambient charge results in an unambiguous decrease in NPS pollution. Under DRTS, a higher ambient charge decreases output but the effect on abatement is ambiguous. Moreover, the marginal effect of a change in the ambient charge is larger under CRTS than DRTS. Our results indicate that, in general, pollution control mechanisms such as ambient charges tend to be more effective under CRTS.
\end{abstract}

Keywords: Environmental Regulation; Nonpoint Source Pollution; Ambient Charges; Cournot Duopoly; Returns to Scale; Strategic Interaction

\section{Introduction}

The regulation of polluting firms by decentralized mechanisms is not only of theoretical interest but is also a policy issue that has assumed considerable significance over the last decade. Nonpoint source (NPS) pollutionthat is, pollution from diffuse sources rather than one specific source - accounts for the majority of present day pollution, especially water pollution. Since NPS pollution originates from several sources, firm specific emissions are virtually impossible to measure and are moreover considerably complicated by issues of moral haz$\operatorname{ard}^{1}$.

A central issue in environmental policy is the design of a regulatory system to address NPS pollution. Commandand-control policies for reducing nonpoint source (NPS) water pollution mandated under the Federal Water Pollution Control Act (FWPCA) have not been particularly

${ }^{1}$ See [1] for a discussion of the ecological, environmental and legislative aspects of NPS pollution. This paper also presents case studies of point and nonpoint source pollution. successful. Ambient charges - charges based on the total amount of pollution irrespective of firm specific originsconstitute one possible mechanism of pollution control. The use of such charges has been widely discussed in the literature ([2-7]). Ambient charges have several advantages over other instruments of pollution control such as quantitative standards, effluent taxes and tradable permits. An effluent tax requires monitoring the amount of pollution generated from each source as well as an assessment of the abatement costs of the polluting firms ([8-12]). However such firm-specific information is difficult to gather and requires effective monitoring involving substantial enforcement costs.

Much of the earlier work on pollution control assumed polluting firms to be price takers. There is some literature on environmental policy under conditions of imperfect competition for point sources of pollution (see $[13,14]$ ). In contrast, environmental policy under NPS pollution and imperfect competition has hardly received much attention in the literature. More recently, [3] explores the 
effectiveness of ambient charges when NPS polluting firms cooperate with each other. Clearly, the issue of competetive interaction among nonpoint source polluters is central to the policy effectiveness of ambient based charges.

The fundamental objective of our paper is to study the effect of ambient charges on total NPS pollution in a Cournot-type duopolistic market. Such a setting clearly brings to the forefront the central issues of competitive interaction and its effect on the optimal design of ambient based pollution charges. Such duopolistic interaction is common in many industries. Prominent examples include Airbus and Boeing, Pepsi and Coca-Cola, Home Depot and Lowes, Canon and Nikon, Kleenex and Puffs, Fedex and UPS, Verizon and AT \& T, PetroChina and Sinopec, etc. Many of these companies are located in industries like transportation, transportation equipment manufacturing, beverages, paper, petroleum, etc. that generate significant pollution and account for considerable pollution abatement operating and capital equipment expenditures.

We assume a two stage duopolistic game. In the first stage of the game, the regulator announces an ambient charge following which both firms choose their pollution abatement technologies. In the second stage after the pollution abatement technology has been chosen, the firms simultaneously choose their optimal output levels. The model assesses strategic firm interaction under alternative assumptions about production technologies (constant and decreasing returns to scale). Simulation is used to evaluate the effect of changes in the ambient charge on total NPS pollution under different technologies.

\section{Ambient Charges, Pollution Abatement Costs and Expenditures}

Periodically, the US Department of Commerce along with the Environmental Protection Agency (EPA) conducts a Pollution Abatement Costs and Expenditures (PACE) survey [15] that constitutes the most comprehensive source of information on capital expenditures and operating costs associated with pollution abatement for about 20,000 plants in the US manufacturing Industry. The most recent PACE data was published in April 2008.

The PACE survey divides pollution abatement costs into two broad categories - pollution abatement operating costs and pollution abatement capital expenditures. Table 1 reports overall data for the US manufacturing sector as well as 12 of the most significant subsectors. For the entire manufacturing sector, pollution abatement operating costs constitute roughly $78 \%$ of total abatement costs while pollution abatement capital expenditures constitute $22 \%$. Of total pollution operating costs, pollution treatment constitutes $52 \%$, disposal $22 \%$, prevention $17 \%$ and recycling $8 \%$. Air pollution abatement makes up the major bulk $(42 \%)$ of operating costs while water
(33\%) and solid waste (26\%) account for remaining costs. As far as capital expenditures are concerned, air pollution capital expenditures makes up nearly $66 \%$ while water $(23 \%)$ and solid waste $(11 \%)$ constitute the remaining expenditure. Among industries with the largest pollution abatement costs are transportation, paper, petroleum, beverages and transportation equipment manufacturing. As noted earlier, several of these industries are characterized by duopolistic competition.

Empirical assessments of ambient charges on pollution are fairly sparse. A recent study by the economy of Estonia $^{2}$ tried to assess if ambient air pollution permits encouraged investment in pollution abatement technology. Pollution is a significant problem in Estonia; the economy's ecological footprint is nearly 4 times larger than is considered economical and its energy intensity usage per capita is among the highest in Europe. A recent study by the National Audit Office of Estonia to assess the effectiveness of ambient air pollution permits revealed several problems. Current charges taxed hazardous pollutantsregardless of the level of danger they represented-at one and the same rate. Pollutants that were produced in large quantities were taxed at a lower rate than others while some pollutants were not taxed at all. In many cases pollution charges were set so low that is was far more economical to pay the charges than incur the cost of pollution abatement technology. The Estonian report highlights the many real world design and implementation problems that underlie ambient charges. Ambient pollution charges are only one part of a more comprehensive environmental regulatory system and are most effective when supported by other legal and administrative measures.

\section{The Model under Constant Returns to Scale (CRTS)}

The basic model relates to a Cournot type setting in which two firms $(i=1,2)$ produce output $q_{i}$. Market inverse demand is given by $P=a-b Q$ where

$Q=q_{1}+q_{2}$ is total output. Market inverse demand, $P$, is positive for $Q<a / b$. For simplicity set $a=b=1$.

Now assume that this duopolistic market is subject to NPS pollution. Let $\alpha_{i}$ for $i=1,2$ be the pollution abatement technology parameter of firm $i$. The pollution from firm $i$ is then equal to $\alpha_{i} q_{i}$ and total pollution is given by $\phi=\alpha_{1} q_{1}+\alpha_{2} q_{2}$. Notice that $\alpha_{i}=0$ corresponds to maximum pollution abatement (zero output pollution) for an individual firm while $\alpha_{i}=1$ corresponds to no pollution abatement $(100 \%$ output pollution). The form of the cost function, given the abatement technology of each firm, is given by:

\footnotetext{
${ }^{2} \mathrm{http} / /$ www.riigikontroll.ee/Suhtedavalikkusega/Pressiteated/tabid/168 /557GetPage/3/557Year/-1/ItemId/9/amid/557/language/en-US/Default .aspx
} 


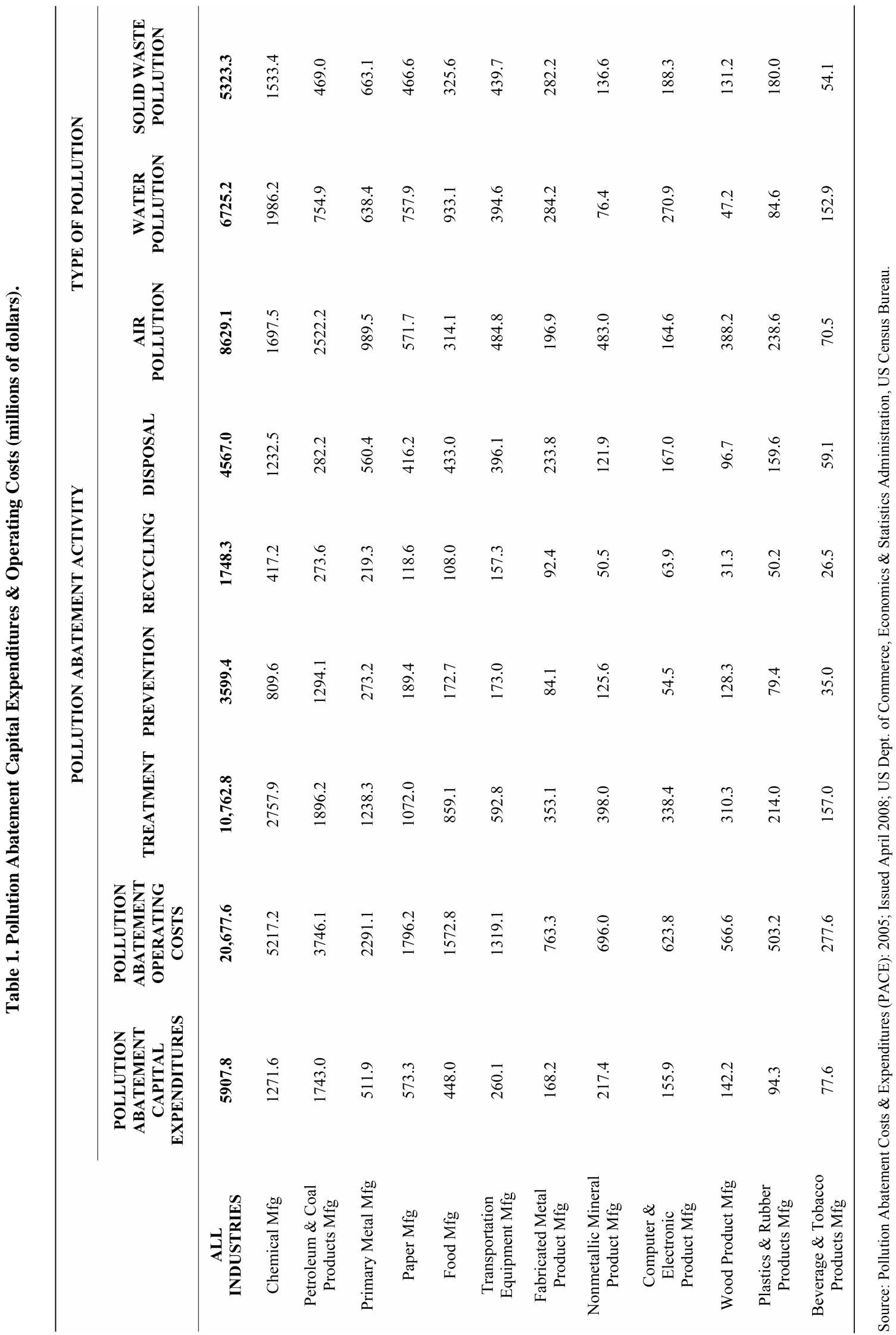




$$
C_{i}=\eta_{i} q_{i}+\left(1-\alpha_{i}\right)^{2} ; \quad i, j=1,2 ; i \neq j
$$

where $0 \leq \alpha_{i} \leq 1$ and $\eta_{i}$ is a positive constant less than 1. Note that $C_{q_{i}}=\eta_{i}, C_{q_{i} q_{i}}=0$ (implying constant marginal cost and constant returns to scale) and $C_{\alpha_{i}}<0, C_{\alpha_{i} \alpha_{i}}>0$. The cost function implies that pollution abatement is costly and is assumed to be separable in output and abatement technology.

In response to NPS pollution, the regulator imposes an ambient pollution standard, $\bar{\phi}$ and a uniform ambient charge, $t$. If total pollution is greater than the ambient standard each firm pays a fine equal to $t(\phi-\bar{\phi})$. On the other hand, if total pollution from both firms is less than the ambient standard, each firm receives a uniform subsidy equal to $t(\phi-\bar{\phi})$. The primary advantage of the ambient charge over other instruments of pollution control is that unlike other instruments where moral hazard is an endemic problem, the ambient charge obviates the need to monitor the firms constantly. The profit function, $\pi_{i}$, in a duopoly setting under these assumptions is given by:

$$
\begin{aligned}
& \pi_{i}=\left(1-q_{i}-q_{j}\right) q_{i}-\left[\eta_{i} q_{i}+\left(1-\alpha_{i}\right)^{2}\right]-t(\phi-\bar{\phi}) ; \\
& i, j=1,2 ; i \neq j
\end{aligned}
$$

The first order conditions for profit maximization imply that:

$$
\frac{\partial \pi_{i}}{\partial q_{i}}=\left[1-2 q_{i}-q_{j}-\eta_{i}-t \alpha_{i}\right]=0 ; \quad i, j=1,2 ; i \neq j
$$

Solving simultaneously for the output reaction functions results in (4) below. The reaction functions capture the effect of one firm's decisions on another and thus capture the interactive element of decision making.

$$
q_{i}^{*}=\frac{\left[1-2 \eta_{i}-2 t \alpha_{i}+\eta_{j}+t \alpha_{j}\right]}{3} ; i, j=1,2 ; i \neq j
$$

Now assume a two stage game. In the first stage of the game, the regulator announces an ambient pollution standard in response to which firms choose their pollution abatement technology parameters given the cost and ambient charge parameters of the model. After the pollution abatement parameters are determined in the first stage, the firms subsequently choose the optimal level of output in the second stage of the game.

Now consider the first stage of the game wherein both firms choose the optimal pollution abatement technologies. Substituting the values of $q_{i}^{*}$ and $q_{j}^{*}$ into the profit function yields

$$
\begin{aligned}
& \pi_{i}^{*}\left(\alpha_{i}, \alpha_{j}, \eta_{i}, \eta_{j}, t, \bar{\phi}\right) \\
& =\left(1-q_{i}^{*}-q_{j}^{*}\right) q_{i}^{*}-\left[\eta_{i} q_{i}^{*}+\left(1-\alpha_{i}\right)^{2}\right] \\
& \quad-t \alpha_{i} q_{i}^{*}-t \alpha_{j} q_{j}^{*}+t \bar{\phi} ; \quad i, j=1,2 ; i \neq j
\end{aligned}
$$

The solution for the optimal pollution abatement technologies is given by differentiating (5) with respect to $\alpha_{i}$. Thus

$$
\begin{aligned}
& \frac{\partial \pi_{i}^{*}}{\partial \alpha_{i}}=\frac{\partial q_{i}^{*}}{\partial \alpha_{i}}\left[1-2 q_{i}^{*}-q_{j}^{*}-\eta_{i}-t \alpha_{i}\right]-\frac{\partial q_{j}^{*}}{\partial \alpha_{i}}\left[q_{i}^{*}+t \alpha_{j}\right] \\
& +2\left(1-\alpha_{i}\right)-t q_{i}^{*}=0 ; \quad i, j=1,2 ; i \neq j
\end{aligned}
$$

Using the first order conditions from (3), the above implies that

$$
\alpha_{i}^{*}=\frac{18+4 t\left(2 \eta_{i}-\eta_{j}-1\right)-7 t^{2} \alpha_{j}^{*}}{18-8 t^{2}} ; i, j=1,2 ; i \neq j
$$

Let $\lambda=\left(18-8 t^{2}\right)$, the denominator of (7). Next note that that $\alpha_{i}^{*}$ is a function of $\alpha_{j}^{*}$. Solving $\alpha_{i}^{*}$ and $\alpha_{j}^{*}$ simultaneously gives the "pollution reaction functions", $\alpha_{i}^{* *}$. Thus

$$
\begin{aligned}
& =\frac{18\left[\lambda-7 t^{2}\right]+4 t\left[\lambda\left(2 \eta_{i}-\eta_{j}-1\right)-7 t^{2}\left(2 \eta_{j}-\eta_{i}-1\right)\right]}{\left(\lambda-7 t^{2}\right)\left(\lambda+7 t^{2}\right)} \\
& i, j=1,2 ; i \neq j
\end{aligned}
$$

Note that (8) depends on the ambient charge $t$ as well as the marginal cost $\left(\eta_{i}, \eta_{j}\right)$ of both firms. Suppose we assume that the marginal cost structure of both firms in the duopolistic market is similar implying that

$\eta_{i}=\eta_{j}=\eta$. Then (8) reduces to the simpler form given by:

$$
\alpha^{* *}=\alpha_{i}^{* *}=\alpha_{j}^{* *}=\frac{18-(4 t)(1-\eta)}{18-t^{2}}
$$

Once the optimal pollution technology is determined, the optimal level of output can be determined in the second stage of the game by substituting (9) into (4). Thus

$$
q^{* *}=q_{i}^{* *}=q_{j}^{* *}=\frac{(1-\eta)-t \alpha^{* *}}{3}
$$

The total pollution at the equilibrium is then given by:

$$
\begin{aligned}
& \phi^{* *}(\eta, t)=\alpha_{i}^{* *} q_{i}^{* *}+\alpha_{j}^{* *} q_{j}^{* *} \\
& =2 \alpha^{* *} q^{* *}=\frac{2 \alpha^{* *}\left[(1-\eta)-t \alpha^{* *}\right]}{3}
\end{aligned}
$$

This "pollution function" is dependent on both marginal cost and the uniform ambient charge. The manner in which the pollution function responds to both these variables is considered in the next section.

\section{The Optimal Pollution Function}

This section derives the optimal pollution function which is useful in developing some underlying intuition of the comparative statics of the model. Holding marginal cost constant, an increase in the ambient charge, $t$, on $\alpha^{* *}, q^{* *}$ and $\phi^{* *}$ is given by:

$$
\frac{\partial \alpha^{* *}}{\partial t}=\frac{4}{\left[18-t^{2}\right]}\left[\frac{t \alpha^{* *}}{2}-(1-\eta)\right]
$$




$$
\begin{gathered}
\frac{\partial q^{* *}}{\partial t}=-\frac{1}{3}\left[\alpha^{* *}+t\left(\frac{\partial \alpha^{* *}}{\partial t}\right)\right] \\
\frac{\partial \phi^{* *}}{\partial t}=\frac{2}{3}\left[\frac{\partial \alpha^{* *}}{\partial t}\left\{(1-\eta)-2 t \alpha^{* *}\right\}-\left\{\alpha^{* *}\right\}^{2}\right]
\end{gathered}
$$

These comparative signs are difficult to sign unambiguously and are therefore simulated for different values of the ambient charge and marginal $\operatorname{cost}^{3}$. The comparative statics consider 3 distinct effects - the effect of a change in the ambient charge $(t)$ on the abatement parameter $\alpha^{* *}$, on optimal output $q^{* *}$ and on the level of pollution, $\phi^{* *}$. First, consider the effect on the abatement parameter of a change in the ambient charge. The simulated values of (12) are negative implying that at given levels of marginal cost, an increase in the ambient charge decreases $\alpha$. Since a lower value of $\alpha$ implies that more pollution is abated, an increase in the ambient charge has the expected outcome of decreasing the quantity of pollution. Equation (13) implies that the increase in the ambient charge has a secondary impact - a higher ambient charge decreases output. The combined effect of higher pollution abatement and lower output is captured by (14) and the simulated results of (14) are reported in Table 2 and depicted in Figure 1. The negative slope of the pollution function is given by (14). It is clear from both Table 2 and the equilibrium pollution function depicted in Figure 1 that an increase in the ambient charge (while holding constant marginal cost) unambiguously lowers total NPS pollution under CRTS.

Next, consider the comparative statics of a change in marginal cost on the abatement parameter, output and pollution while holding constant the ambient charge, $t$.

$$
\begin{gathered}
\frac{\partial \alpha^{* *}}{\partial \eta}=\frac{4 t}{18-t^{2}} \geq 0 \\
\frac{\partial q^{* *}}{\partial \eta}=-(1 / 3)\left[1+t \frac{\partial \alpha^{* *}}{\partial \eta}\right]<0 \\
\frac{\partial \phi^{* *}}{\partial \eta}=\frac{2}{3}\left[\frac{\partial \alpha^{* *}}{\partial \eta}\left\{(1-\eta)-2 t \alpha^{* *}\right\}-\left\{\alpha^{* *}\right\}\right]
\end{gathered}
$$

The first result, (15), is unambiguously positive and implies that an increase in marginal cost, holding constant the ambient charge, increases $\alpha$. Since a higher value of $\alpha$ implies that less pollution is abated, an increase in marginal cost has the effect of increasing pollution. The intuition here is that since pollution abatement is costly, the firm responds to an increase in marginal cost by decreasing pollution abatement and thereby in-

${ }^{3}$ Equations (10) and (11) require that $(1-\eta)>t \alpha^{* *}$ for both equilibrium output $\left(q^{* *}\right)$ and equilibrium pollution $\left(\phi^{* *}\right)$ to be positive under CRTS. Equation 12 is unambiguously negative if a more stringent restriction of the form $(1-\eta)>(1 / 2) t \alpha^{* *}$ is imposed on the comparative statics results. The subsequent results assume these restrictions. creasing total pollution. Equation (16) is unambiguously negative implying that an increase in marginal cost decreases output which consequently leads to lower pollution. Equations (15) and (16) thus imply that an increase in marginal cost results in two countervailing effects. While lower pollution abatement serves to increase total pollution, the decrease in output works in the opposite direction to decreases total pollution. Equation (17) is simulated for different values of the ambient charge and marginal cost (see Table 3). Table 3 implies that even though (15) and (16) work in opposite direction, the net effect of an increase in marginal cost is to decrease total NPS pollution under CRTS.

This result is also depicted in Figure 1. The equilibrium pollution function is shown in Figure 1 for two specific values of marginal cost $(\eta=0.10, \eta=0.20)$. Holding constant marginal cost along each pollution curve, it is evident that as the ambient charge increases, equilibrium NPS pollution decreases. Holding constant the ambient charge, a higher (lower) marginal cost shifts the pollution function downwards (upwards). In essence, for a given ambient charge, a higher marginal cost decreases total NPS pollution under CRTS.

The extent to which these results can be generalized depends on several factors. The assumption of a Cournot duopoly clearly imposes a particular type of firm structure. A previous paper by us [16] considers questions similar to those in this paper but under a Bertrand duopoly. In addition to firm structure, the results are affected by the assumed cost structure. In the next section, we extend the results of this section to the case of decreasing returns to scale.

\section{The Model under Decreasing Returns to Scale (DRTS)}

Now suppose the cost function is given by:

$$
C_{i}=\eta_{i} q_{i}^{2}+\left(1-\alpha_{i}\right)^{2} ; i, j=1,2 ; i \neq j
$$

where $C_{q_{i}}=2 \eta_{i} q_{i}>0, \quad C_{q_{i}, q_{i}}=2 \eta_{i}>0 \quad$ (implying increasing marginal cost and decreasing returns to scale) and $C_{\alpha_{i}}<0$. Assuming that the marginal cost structures of both firms are similar (i.e. $\eta_{i}=\eta_{j}$ ), the first order condition for maximization under DRTS is given by:

$$
\frac{\partial \pi_{i}}{\partial q_{i}}=1-2 q_{i}(1+\eta)-q_{j}-t \alpha_{i}=0 \quad i, j=1,2 ; i \neq j
$$

Solving for both outputs simultaneously yields the reaction functions:

$$
q_{i}^{*}=\frac{1+2 \eta+t \alpha_{j}-2 t \alpha_{i}(1+\eta)}{\delta} \quad i, j=1,2 ; i \neq j
$$

where $\delta=\left[4(1+\eta)^{2}-1\right]$. Differentiating $\pi^{*}\left(\alpha_{i}, \alpha_{j}, \eta, t, \bar{\phi}\right)$ with respect to $\alpha_{i}$ results in 


$$
\begin{aligned}
& \frac{\partial \pi_{i}^{*}}{\partial \alpha_{i}}=\frac{\partial q_{i}^{*}}{\partial \alpha_{i}}\left[1-2 q_{i}^{*}(1+\eta)-q_{j}^{*}-t \alpha_{i}\right] \\
& -\frac{\partial q_{j}^{*}}{\partial \alpha_{i}}\left[q_{i}^{*}+t \alpha_{j}\right]+2\left(1-\alpha_{i}\right)-t q_{i}^{*}=0
\end{aligned}
$$

Utilizing the first order conditions given by (19), the optimal values of $\alpha_{i}$ are given by:

$$
\begin{aligned}
& \alpha_{i}^{*}=\frac{2 \delta^{2}-\alpha_{j} t^{2}[2 \delta+1]-(1+\delta) t[1+2 \eta]}{\left[2 \delta^{2}-\left(2 t^{2}\right)(1+\eta)(1+\delta)\right]} \\
& i, j=1,2 ; i \neq j
\end{aligned}
$$

Let $D=\left[2 \delta^{2}-\left(2 t^{2}\right)(1+\eta)(1+\delta)\right]$, the denominator of (21). Substituting for $\alpha_{j}^{*}$ in the expression above and after considerable simplification ${ }^{4}$, the optimal pollution abatement technologies (pollution reaction functions) as a function of the parameters $\eta$ and $t$ are given by:

$$
\alpha_{i}^{* *}=\alpha_{j}^{* *}=\alpha^{* *}=\frac{\Omega}{\Delta} \quad i, j=1,2 ; i \neq j
$$

where $\Omega=\left[2 \delta^{2}-(1+\delta)(t)(1+2 \eta)\right]$;

$\Delta=\left[D+t^{2}(2 \delta+1)\right]$

Substituting $\alpha^{* *}$ into (20) gives:

$$
q^{* *}=q_{i}^{* *}=q_{j}^{* *}=\frac{1}{\delta}\left[(1+2 \eta)\left\{1-t \alpha^{* *}\right\}\right]
$$

The level of total NPS pollution under DRTS is then given by:

$$
\phi^{* *}=2 \alpha^{* *} q^{* *}=\frac{2}{\delta}\left[\alpha^{* *}\right]\left[(1+2 \eta)\left\{1-t \alpha^{* *}\right\}\right]
$$

The comparative statics of a change in the ambient charge on the abatement parameter, output and pollution is given by:

$$
\begin{gathered}
\frac{\partial \alpha^{* *}}{\partial t}=\frac{-[(1+\delta)(1+2 \eta)][\Delta]}{\Delta^{2}}-\frac{\left[\frac{\partial D}{\partial t}+(2 t)(2 \delta+1)\right][\Omega]}{\Delta^{2}} \\
\frac{\partial q^{* *}}{\partial t}=-\frac{(1+2 \eta)}{\delta}\left[\alpha^{* *}+t\left(\frac{\partial \alpha^{* *}}{\partial t}\right)\right] \\
\frac{\partial \phi^{* *}}{\partial t}=2\left[q^{* *} \frac{\partial \alpha^{* *}}{\partial t}+\alpha^{* *}\left(\frac{\partial q^{* *}}{\partial t}\right)\right]
\end{gathered}
$$

where $\frac{\partial D}{\partial t}=(-4 t)(1+\eta)(1+\delta)$. Since the sign of (24)

${ }^{4} \mathrm{~A}$ useful result in simplifying (15) to arrive at the form given by (16) is to recognize that

$$
\left[D^{2}-\left(t^{2}\{2 \delta+1\}\right)^{2}\right]=\left[D-t^{2}(2 \delta+1)\right]\left[D+t^{2}(2 \delta+1)\right] .
$$

cannot be unambiguously determined, we simulated (24)-(26) for different ambient charge $(t)$ and marginal cost $(\eta)$ values. The results indicate that while the effect of change in the ambient charge on the abatement parameter is ambiguous under DRTS, the effect of a change in the ambient charge on output is unambiguously negative. Equation (26) indicates that the effect of a change in the ambient charge on NPS pollution is composed of two effects - the effect on the abatement parameter and the effect on output. The first of these effects is ambiguous but the second is unambiguously negative. The net effect of a change in the ambient charge on total NPS pollution is reported in Table 4. These are however all negativein effect, the decline in output resulting from an increase in the ambient charge overwhelms the ambiguous effect on pollution abatement. The net effect is to reduce NPS pollution under DRTS.

While an increase in the ambient charge reduces total pollution under both CRTS and DRTS, the marginal effect of a change in the ambient charge is larger under CRTS. (This is apparent from a comparison of the values in Tables 2 and 4). The reason for the more pronounced impact under CRTS is due to the fact that an increase in the ambient charge leads to more pollution abatement under CRTS while this effect is ambiguous under DRTS.

The same notion is highlighted in Figure 1. The pollution functions under both CRTS and DRTS are downward sloping indicating that an increase in the ambient charge leads to a decline in total NPS pollution. The pollution functions under CRTS lie on a lower plan than DRTS indicating that for similar values of marginal cost, total NPS pollution under CRTS is less than DRTS.

Finally, consider the impact of a change in marginal cost while holding constant the ambient charge. The comparative statics of a change in $\eta$ are given below:

$$
\begin{aligned}
& \frac{\partial \alpha^{* *}}{\partial \eta}=\frac{\left[4 \delta\left(\frac{\partial \delta}{\partial \eta}\right)-(2)(1+\delta)(t)-\left(\frac{\partial \delta}{\partial \eta}\right)(t)(1+2 \eta)\right][\Delta]}{[\Delta]^{2}} \\
& -\frac{\left[\frac{\partial D}{\partial \eta}+2 t^{2} \frac{\partial \delta}{\partial \eta}\right][\Omega]}{[\Delta]^{2}}
\end{aligned}
$$

$$
\begin{aligned}
\frac{\partial q^{* *}}{\partial \eta}=\frac{\left[2-(t)(1+2 \eta)\left(\frac{\partial \alpha^{* *}}{\partial \eta}\right)-2 t \alpha^{* *}\right][\delta]}{[\delta]^{2}} & -\frac{\left[\frac{\partial \delta}{\partial \eta}\right]\left[\left(1+2 \eta-t \alpha^{* *}(1+2 \eta)\right)\right]}{[\delta]^{2}}
\end{aligned}
$$


Table 2. The marginal effect of a change in the ambient charge on NPS pollution under CRTS (for given levels of marginal cost).

\begin{tabular}{rrrrrrrrrrr}
\hline & $\boldsymbol{t}=\mathbf{0 . 1 0}$ & $\boldsymbol{t}=\mathbf{0 . 2 0}$ & $\boldsymbol{t}=\mathbf{0 . 3 0}$ & $\boldsymbol{t}=\mathbf{0 . 4 0}$ & $\boldsymbol{t}=\mathbf{0 . 5 0}$ & $\boldsymbol{t}=\mathbf{0 . 6 0}$ & $\boldsymbol{t}=\mathbf{0 . 7 0}$ & $\boldsymbol{t}=\mathbf{0 . 8 0}$ & $\boldsymbol{t}=\mathbf{0 . 9 0}$ & $\boldsymbol{t}=\mathbf{1 . 0 0}$ \\
\hline $\boldsymbol{\eta}=\mathbf{0 . 1 0}$ & -0.7298 & -0.6786 & -0.6326 & -0.5912 & -0.5540 & -0.5206 & -0.4907 & -0.4639 & -0.4401 & -0.4190 \\
$\boldsymbol{\eta}=\mathbf{0 . 2 0}$ & -0.7111 & -0.6660 & -0.6259 & -0.5902 & -0.5585 & -0.5306 & -0.5061 & -0.4848 & -0.4667 & -0.4514 \\
$\boldsymbol{\eta}=\mathbf{0 . 3 0}$ & -0.6953 & -0.6565 & -0.6224 & -0.5925 & -0.5666 & -0.5444 & -0.5258 & -0.5105 & -0.4985 & -0.4898 \\
$\boldsymbol{\eta}=\mathbf{0 . 4 0}$ & -0.6826 & -0.6501 & -0.6220 & -0.5982 & -0.5783 & -0.5622 & -0.5497 & -0.5409 & -0.5356 & -0.5340 \\
$\boldsymbol{\eta}=\mathbf{0 . 5 0}$ & -0.6728 & -0.6467 & -0.6249 & -0.6072 & -0.5936 & -0.5839 & -0.5780 & -0.5760 & -0.5780 & -0.5842 \\
$\boldsymbol{\eta}=\mathbf{0 . 6 0}$ & -0.6661 & -0.6463 & -0.6309 & -0.6197 & -0.6125 & -0.6094 & -0.6105 & -0.6158 & -0.6256 & -0.6402 \\
$\boldsymbol{\eta}=\mathbf{0 . 7 0}$ & -0.6623 & -0.6490 & -0.6401 & -0.6354 & -0.6350 & -0.6389 & -0.6473 & -0.6604 & -0.6785 & -0.7021 \\
$\boldsymbol{\eta}=\mathbf{0 . 8 0}$ & -0.6615 & -0.6548 & -0.6525 & -0.6546 & -0.6611 & -0.6723 & -0.6884 & -0.7097 & -0.7367 & -0.7699 \\
$\boldsymbol{\eta}=\mathbf{0 . 9 0}$ & -0.6637 & -0.6637 & -0.6681 & -0.6771 & -0.6909 & -0.7096 & -0.7337 & -0.7637 & -0.8001 & -0.8437 \\
$\boldsymbol{\eta}=\mathbf{1 . 0 0}$ & -0.6689 & -0.6756 & -0.6869 & -0.7030 & -0.7242 & -0.7508 & -0.7834 & -0.8224 & -0.8687 & -0.9233 \\
\hline
\end{tabular}

Table 3. The marginal effect of a change in marginal cost on NPS pollution under CRTS (for given levels of the ambient charge).

\begin{tabular}{rrrrrrrrrrrr}
\hline & $\boldsymbol{t}=\mathbf{0 . 1 0}$ & $\boldsymbol{t}=\mathbf{0 . 2 0}$ & $\boldsymbol{t}=\mathbf{0 . 3 0}$ & $\boldsymbol{t}=\mathbf{0 . 4 0}$ & $\boldsymbol{t}=\mathbf{0 . 5 0}$ & $\boldsymbol{t}=\mathbf{0 . 6 0}$ & $\boldsymbol{t}=\mathbf{0 . 7 0}$ & $\boldsymbol{t}=\mathbf{0 . 8 0}$ & $\boldsymbol{t}=\mathbf{0 . 9 0}$ & $\boldsymbol{t}=\mathbf{1 . 0}$ \\
\hline $\boldsymbol{\eta}=\mathbf{0 . 1 0}$ & -0.6433 & -0.6261 & -0.6149 & -0.6094 & -0.6094 & -0.6147 & -0.6254 & -0.6413 & -0.6626 & -0.6893 \\
$\boldsymbol{\eta}=\mathbf{0 . 2 0}$ & -0.6462 & -0.6321 & -0.6240 & -0.6218 & -0.6253 & -0.6344 & -0.6491 & -0.6695 & -0.6957 & -0.7280 \\
$\boldsymbol{\eta}=\mathbf{0 . 3 0}$ & -0.6492 & -0.6381 & -0.6332 & -0.6342 & -0.6411 & -0.6540 & -0.6728 & -0.6977 & -0.7289 & -0.7668 \\
$\boldsymbol{\eta}=\mathbf{0 . 4 0}$ & -0.6522 & -0.6441 & -0.6423 & -0.6466 & -0.6570 & -0.6736 & -0.6965 & -0.7259 & -0.7621 & -0.8055 \\
$\boldsymbol{\eta}=\mathbf{0 . 5 0}$ & -0.6551 & -0.6501 & -0.6514 & -0.6590 & -0.6729 & -0.6932 & -0.7202 & -0.7541 & -0.7953 & -0.8443 \\
$\boldsymbol{\eta}=\mathbf{0 . 6 0}$ & -0.6581 & -0.6561 & -0.6605 & -0.6714 & -0.6888 & -0.7129 & -0.7439 & -0.7823 & -0.8285 & -0.8830 \\
$\boldsymbol{\eta}=\mathbf{0 . 7 0}$ & -0.6611 & -0.6621 & -0.6696 & -0.6837 & -0.7046 & -0.7325 & -0.7676 & -0.8105 & -0.8617 & -0.9218 \\
$\boldsymbol{\eta}=\mathbf{0 . 8 0}$ & -0.6641 & -0.6681 & -0.6787 & -0.6961 & -0.7205 & -0.7521 & -0.7913 & -0.8387 & -0.8949 & -0.9606 \\
$\boldsymbol{\eta}=\mathbf{0 . 9 0}$ & -0.6670 & -0.6741 & -0.6878 & -0.7085 & -0.7364 & -0.7717 & -0.8150 & -0.8669 & -0.9280 & -0.9993 \\
$\boldsymbol{\eta}=\mathbf{1 . 0}$ & -0.6700 & -0.6801 & -0.6970 & -0.7209 & -0.7522 & -0.7913 & -0.8387 & -0.8951 & -0.9612 & -1.0381 \\
\hline
\end{tabular}

Table 4. The marginal effect of a change in the ambient charge on NPS pollution under DRTS (for given levels of marginal cost).

\begin{tabular}{rrrrrrrrrrr}
\hline & $\boldsymbol{t}=\mathbf{0 . 1 0}$ & $\boldsymbol{t}=\mathbf{0 . 2 0}$ & $\boldsymbol{t}=\mathbf{0 . 3 0}$ & $\boldsymbol{t}=\mathbf{0 . 4 0}$ & $\boldsymbol{t}=\mathbf{0 . 5 0}$ & $\boldsymbol{t}=\mathbf{0 . 6 0}$ & $\boldsymbol{t}=\mathbf{0 . 7 0}$ & $\boldsymbol{t}=\mathbf{0 . 8 0}$ & $\boldsymbol{t}=\mathbf{0 . 9 0}$ & $\boldsymbol{t}=\mathbf{1 . 0}$ \\
\hline $\boldsymbol{\eta}=\mathbf{0 . 1 0}$ & -0.6939 & -0.6458 & -0.6032 & -0.5656 & -0.5325 & -0.5035 & -0.4783 & -0.4566 & -0.4383 & -0.4231 \\
$\boldsymbol{\eta}=\mathbf{0 . 2 0}$ & -0.6457 & -0.6045 & -0.5686 & -0.5377 & -0.5113 & -0.4890 & -0.4707 & -0.4563 & -0.4456 & -0.4386 \\
$\boldsymbol{\eta}=\mathbf{0 . 3 0}$ & -0.6045 & -0.5686 & -0.5379 & -0.5119 & -0.4904 & -0.4730 & -0.4597 & -0.4504 & -0.4450 & -0.4439 \\
$\boldsymbol{\eta}=\mathbf{0 . 4 0}$ & -0.5687 & -0.5370 & -0.5103 & -0.4882 & -0.4703 & -0.4566 & -0.4469 & -0.4412 & -0.4396 & -0.4425 \\
$\boldsymbol{\eta}=\mathbf{0 . 5 0}$ & -0.5371 & -0.5089 & -0.4855 & -0.4663 & -0.4513 & -0.4403 & -0.4332 & -0.4302 & -0.4313 & -0.4369 \\
$\boldsymbol{\eta}=\mathbf{0 . 6 0}$ & -0.5090 & -0.4838 & -0.4629 & -0.4462 & -0.4334 & -0.4245 & -0.4194 & -0.4182 & -0.4212 & -0.4286 \\
$\boldsymbol{\eta}=\mathbf{0 . 7 0}$ & -0.4838 & -0.4610 & -0.4424 & -0.4276 & -0.4166 & -0.4093 & -0.4057 & -0.4059 & -0.4102 & -0.4187 \\
$\boldsymbol{\eta}=\mathbf{0 . 8 0}$ & -0.4611 & -0.4404 & -0.4236 & -0.4105 & -0.4009 & -0.3949 & -0.3924 & -0.3936 & -0.3987 & -0.4080 \\
$\boldsymbol{\eta}=\mathbf{0 . 9 0}$ & -0.4405 & -0.4216 & -0.4064 & -0.3946 & -0.3863 & -0.3812 & -0.3796 & -0.3815 & -0.3872 & -0.3969 \\
$\boldsymbol{\eta}=\mathbf{1 . 0}$ & -0.4217 & -0.4043 & -0.3905 & -0.3799 & -0.3725 & -0.3683 & -0.3673 & -0.3698 & -0.3757 & -0.3857 \\
\hline
\end{tabular}




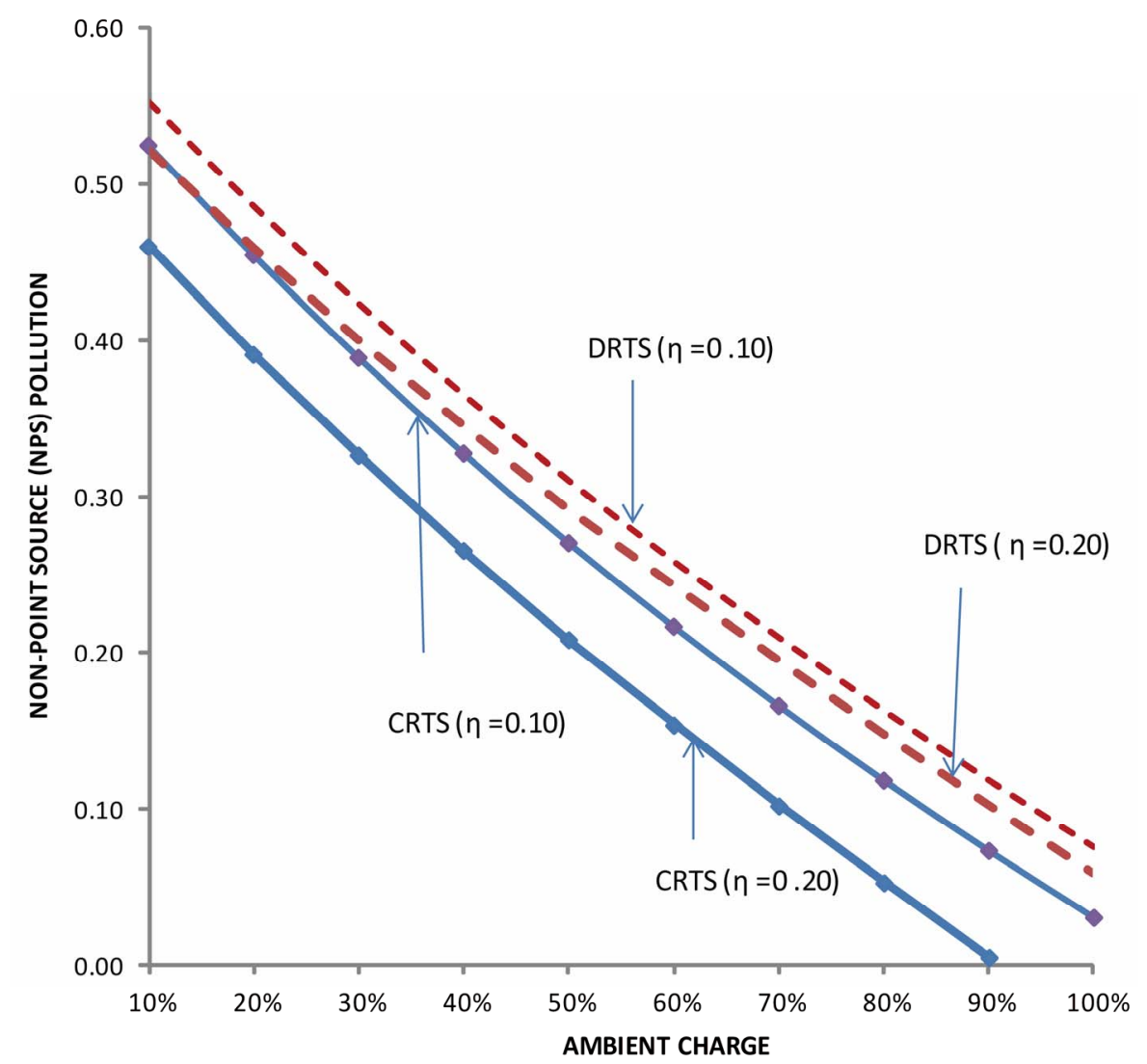

Figure 1. Pollution function under CRTS and DRTS.

$$
\frac{\partial \phi^{* *}}{\partial \eta}=2\left[q^{* *} \frac{\partial \alpha^{* *}}{\partial \eta}+\alpha^{* *}\left(\frac{\partial q^{* *}}{\partial \eta}\right)\right]
$$

where $\Delta=D+t^{2}(2 \delta+1) ; \frac{\partial \delta}{\partial \eta}=8(1+\eta)$;

$$
\frac{\partial D}{\partial \eta}=\left(\frac{\partial \delta}{\partial \eta}\right)\left[4 \delta-2 t^{2}(1+\eta)\right]-2 t^{2}(1+\delta)
$$

The signs of these comparative statics are not obvious. The simulated value of (27) indicates that an increase in marginal cost leads to an increase in the value of the abatement parameter. Since a higher value of the abatement parameter indicates a lower level of pollution abatement, total pollution increases. In essence, when marginal cost goes up costly pollution abatement is scaled back, leading to more pollution. Equation (28) indicates that when marginal cost increases, output falls which consequently leads to less pollution. Even though both these effects work in opposite directions, the net effect of an increase in marginal cost on pollution given by (29) is unambiguously negative. The simulated effect of an increase in marginal cost on pollution is reported in Table 5. It is clear from a comparison of Tables $\mathbf{3}$ and 5 that this effect is more pronounced under CRTS than under DRTS. Figure 1 reinforces the same notion. Holding constant the ambient charge, a higher (lower) marginal cost under both CRTS and DRTS shifts the pollution function downwards (upwards). In essence, for a given ambient charge, a higher marginal cost decreases total NPS pollution under CRTS and DRTS.

The results for decreasing returns to scale above can be extended to the case of increasing returns to scale (IRTS). Under IRTS, the cost structure is given by:

$$
C_{i}=\eta_{i} q_{i}+\delta_{i} q_{i}^{2}+\left(1-\alpha_{i}\right)^{2} ; i, j=1,2 ; i \neq j
$$

where $\eta_{i}>0 ; \delta_{i}<0$. Thus, $C_{q_{i}}=\eta_{i}+2 \delta_{i} q_{i}>0$ if $q_{i}>\frac{-\eta_{i}}{2 \delta_{i}}$ and $C_{q_{i}, q_{i}}=2 \delta_{i}<0$ implying that marginal cost is positive but increases at a diminishing rate. The results for IRTS are not reported here but can be easily derived in a manner similar to the CRTS and DRTS cases considered above.

\section{Conclusions}

Environmental regulation under conditions of imperfect competition for point sources of pollution has been well analyzed in the literature. In contrast, environmental policy under conditions of imperfect competition for nonpoint sources of pollution has received far less attention in the literature. 
Table 5. The marginal effect of a change in marginal cost on NPS pollution under DRTS (for given levels of ambient charge).

\begin{tabular}{rrrrrrrrrrr}
\hline & $\boldsymbol{t}=\mathbf{0 . 1 0}$ & $\boldsymbol{t}=\mathbf{0 . 2 0}$ & $\boldsymbol{t}=\mathbf{0 . 3 0}$ & $\boldsymbol{t}=\mathbf{0 . 4 0}$ & $\boldsymbol{t}=\mathbf{0 . 5 0}$ & $\boldsymbol{t}=\mathbf{0 . 6 0}$ & $\boldsymbol{t}=\mathbf{0 . 7 0}$ & $\boldsymbol{t}=\mathbf{0 . 8 0}$ & $\boldsymbol{t}=\mathbf{0 . 9 0}$ & $\boldsymbol{t}=\mathbf{1 . 0}$ \\
\hline $\boldsymbol{\eta}=\mathbf{0 . 1 0}$ & -0.3343 & -0.2859 & -0.2452 & -0.2123 & -0.1872 & -0.1700 & -0.1609 & -0.1602 & -0.1682 & -0.1854 \\
$\boldsymbol{\eta}=\mathbf{0 . 2 0}$ & -0.2986 & -0.2572 & -0.2218 & -0.1921 & -0.1681 & -0.1497 & -0.1371 & -0.1305 & -0.1300 & -0.1362 \\
$\boldsymbol{\eta}=\mathbf{0 . 3 0}$ & -0.2678 & -0.2319 & -0.2006 & -0.1737 & -0.1511 & -0.1326 & -0.1184 & -0.1084 & -0.1028 & -0.1018 \\
$\boldsymbol{\eta}=\mathbf{0 . 4 0}$ & -0.2414 & -0.2098 & -0.1819 & -0.1574 & -0.1363 & -0.1183 & -0.1034 & -0.0916 & -0.0829 & -0.0774 \\
$\boldsymbol{\eta}=\mathbf{0 . 5 0}$ & -0.2186 & -0.1905 & -0.1654 & -0.1431 & -0.1234 & -0.1062 & -0.0912 & -0.0785 & -0.0680 & -0.0598 \\
$\boldsymbol{\eta}=\mathbf{0 . 6 0}$ & -0.2186 & -0.1905 & -0.1654 & -0.1431 & -0.1234 & -0.1062 & -0.0912 & -0.0785 & -0.0680 & -0.0597 \\
$\boldsymbol{\eta}=\mathbf{0 . 7 0}$ & -0.1815 & -0.1588 & -0.1382 & -0.1195 & -0.1024 & -0.0869 & -0.0728 & -0.0599 & -0.0481 & -0.0372 \\
$\boldsymbol{\eta}=\mathbf{0 . 8 0}$ & -0.1663 & -0.1457 & -0.1269 & -0.1097 & -0.0939 & -0.0792 & -0.0657 & -0.0531 & -0.0412 & -0.0299 \\
$\boldsymbol{\eta}=\mathbf{0 . 9 0}$ & -0.1530 & -0.1342 & -0.1169 & -0.1010 & -0.0863 & -0.0725 & -0.0596 & -0.0474 & -0.0357 & -0.0243 \\
$\boldsymbol{\eta}=\mathbf{1 . 0}$ & -0.1412 & -0.1239 & -0.1080 & -0.0933 & -0.0796 & -0.0667 & -0.0544 & -0.0426 & -0.0312 & -0.0200 \\
\hline
\end{tabular}

In this paper, we model the imposition of ambient charges as a mechanism of pollution control in a Cournot duopoly. The model assesses strategic firm interaction under two alternative assumptions about returns to scale. Under CRTS, an increase in the ambient charge results in two distinct effects. The primary effect of a higher ambient charge is to increase pollution abatement (and thus decrease pollution) while the secondary effect is to lower output. The effect of higher pollution abatement and lower output reinforce each other so that an increase in the ambient charge results in an unambiguous decrease in total pollution under CRTS. Under DRTS, a higher ambient charge decreases output but the effect on abatement is ambiguous. However, the net effect is to decrease pollution though the impact of an ambient charge on pollution reduction is lower under DRTS than CRTS.

Our model also indicates that for a given ambient charge, an increase in marginal cost results in two countervailing effects. A higher marginal cost decreases pollution abatement (and thus increases pollution) while also reducing output which results in lower pollution. The net effect of higher marginal cost is to reduce pollution but this effect is more pronounced under CRTS than DRTS. The implication is that NPS pollution mechanisms like ambient charges tend to be more effective under CRTS than DRTS.

\section{REFERENCES}

[1] K. Loague and D. L.Corwin, "Point and Nonpoint Source Pollution," John Wiley \& Sons, Hoboken, 2005, pp. 1427-1439.

[2] J. Suter, C. Vossler, G. Poe and K. Segerson, "Experiments on Damage-Based Ambient Taxes for Nonpoint Source Polluters," American Journal of Agricultural Economics, Vol. 90, No. 1, 2008, pp. 86-102. doi:10.1111/j.1467-8276.2007.01055.x
[3] G. Poe, W. Schulze, K. Segerson, J. Suter and C. Vossler, "Exploring the Performance of Ambient Based Policy Instruments when Nonpoint Source Polluters Can Cooperate," American Journal of Agricultural Economics, Vol. 86, No. 5, 2004, pp. 1203-1210. doi:10.1111/j.0002-9092.2004.00665.x

[4] K. Segerson, "Uncertainty and Incentives for Non-Point Pollution Control," Journal of Environmental Economics and Management, Vol. 15, No. 1, 1988, pp. 87-98.

[5] A. P. Xepapadeas, "Environmental Policy under Imperfect Information: Incentives and Moral Hazard," Journal of Environmental Economics and Management, Vol. 20, No. 2, 1991, pp. 113-126.

[6] A. P. Xepapadeas, "Environmental Policy Design and Dynamic Non-Point Source Pollution," Journal of Environmental Economics and Management, Vol. 23, No. 1, 1992, pp. 22-39.

[7] A. P. Xepapadeas, "Observability and Choice of Instrument Mix in the Control of Externalities," Journal of Public Economics, Vol. 56, No. 3, 1995, pp. 485-498.

[8] W. Baumol and W. Oates, "The Use of Standards and Prices for Protection of the Environment," Swedish Journal of Economics, Vol. 73, No. 1, 1971, pp. 42-54. doi: $10.2307 / 3439132$

[9] W. Baumol, "On Taxation and the Control of Externalities," American Economic Review, Vol. 62, No. 3, 1972, pp. 307-322.

[10] M. Weitzman, "Prices vs. Quantities," Review of Economic Studies, Vol. 41, No. 4, 1994, pp. 477-491. doi: $10.2307 / 2296698$

[11] J. Harford, "Firm Behavior under Imperfectly Enforceable Pollution Standards and Taxes," Journal of Environmental Economics and Management, Vol. 5, No. 1, 1978, pp. 26-43. doi:10.1016/0095-0696(78)90003-7

[12] M. Stimming, "Capital Accumulation Games under Environmental Regulation and Duopolistic Competition," Journal of Economics, Vol. 69, No. 3, 1999, pp. 267-287. doi:10.1007/BF01231162 
[13] T. Requate, "Pollution Control under Imperfect Competition: Asymmetric Bertrand Duopoly with Linear Technologies," Journal of Institutional and Theoretical Economics, Vol. 149, No. 2, 1993, pp. 415-442.

[14] T. Requate, "Pollution Control in a Cournot Duopoly via Taxes or Permits," Journal of Economics, Vol. 58, No. 3, 1993, pp. 255-291. doi:10.1007/BF01235250

[15] US Department of Commerce, "Pollution Abatement
Costs and Expenditures (PACE): 2005," US Department of Commerce, Economics and Statistics Administration, US Census Bureau, 2008.

[16] S. Ganguli and S. Raju, "Perverse Environmental Effects of Ambient Charges in a Bertrand Duopoly," Journal of Environmental Economics and Policy, Vol. 1, No. 3, 2012, pp. 289-296. 